\title{
NON-INVASIVE SURVEY OF OLD PAINTINGS USING VNIR HYPERSPECTRAL SENSOR
}

\author{
E. Matouskova ${ }^{\mathrm{a}}$, K. Pavelka ${ }^{\mathrm{a}}$, Z. Svadlenkova ${ }^{\mathrm{b}}$ \\ ${ }^{a}$ Czech Technical University in Prague, Faculty of Civil Engineering, Department of Mapping and Cartography, \\ Thakurova 7, 166 29, Praha 6, Czech Republic (eva.matouskova, pavelka)@ fsv.cvut.cz \\ ${ }^{\mathrm{b}}$ Municipal library of Prague, Marianske namesti 1/98, 110 00, Praha 1, Czech Republic, \\ zsvadlenkova@gmail.com
}

KEY WORDS: Hyperspectral imaging, Painting, VNIR, Cultural heritage documentation

\begin{abstract}
:
Hyperspectral imaging is relatively new method developed primarily for army applications with respect to detection of possible chemical weapon existence and as an efficient assistant for a geological survey. The method is based on recording spectral profile for many hundreds of narrow spectral band. The technique gives full spectral curve of explored pixel which is an unparalleled signature of pixels material. Spectral signatures can then be compared with pre-defined spectral libraries or they can be created with respect to application.

A new project named "New Modern Methods of Non-invasive Survey of Historical Site Objects" started at CTU in Prague with the New Year. The project is designed for 4 years and is funded by the Ministry of Culture in the Czech Republic. It is focused on material and chemical composition, damage diagnostics, condition description of paintings, images, construction components and whole structure object analysis in cultural heritage domain.

This paper shows first results of the project on painting documentation field as well as used instrument. Hyperspec VNIR by Headwall Photonics was used for this analysis. It operates in the spectral range between 400 and $1000 \mathrm{~nm}$. Comparison with infrared photography is discussed. The goal of this contribution is a non-destructive deep exploration of specific paintings. Two original 17th century paintings by Flemish authors Thomas van Apshoven ("On the Road") and David Teniers the Younger ("The Interior of a Mill") were chosen for the first analysis with a kind permission of academic painter Mr. M. Martan. Both paintings oil painted on wooden panel. This combination was chosen because of the possibility of underdrawing visualization which is supposed to be the most uncomplicated painting combination for this type of analysis.
\end{abstract}

\section{INTRODUCTION}

Documentation of cultural heritage is crucial for its identification, interpretation, protection and also for future restoration and renovation processes. Many different documentation techniques are used these days, one can mention photogrammetry [1],[2], laser scanning [3], [4], [5], their combination [6], [7], [8] or various GIS tools [9], [10], [11]. These techniques are very powerful in terms of size and structure, but they cannot deal with the spectral response, which leads to determination of certain material and its characteristics. Hyperspectral imagery can provide unique information regarding this matter and is very powerful. When historical paintings are concerned it gives remarkable results regarding color, material and chemical composition of examined historical object. It is a remarkable non-invasive method for exploring cultural heritage compounds. It was already used by several authors [12], [13].

A new project named "New Modern Methods of Noninvasive Survey of Historical Site Objects" has started at the Czech Technical University in Prague in March 2013 with the duration of 4 years. In this project cultural heritage objects will be investigated and documented. The funding is provided by the Czech Ministry of Culture and fulfillment of specific issues mentioned in the registration like material and chemical composition, damage diagnostics, condition description of paintings, images, construction components and whole structure object analysis are expected.
This paper deals with the VNIR hyperspectral imaging and IR reflectrography for possible painting documentation and conservation.

\section{THE HYPERSPECTRAL INSTRUMENT}

For this project an Aseries hyperspectral VNIR camera Hyperspec VNIR manufactured by Headwall Photononics Inc. [14] is used. Headwall Photonics' Hyperspec imaging spectrometer platform is built on a totally reflective concentric, f/2 optical design. The camera is lens-based, thus equipped with C-Mount $35 \mathrm{~mm}$ objective and $18 \mathrm{~mm}$ long and 25um wide slit. The operational wavelength ranges between 400 to $1000 \mathrm{~nm}$ and the focal plane size is 1004 spatial and 810 spectral bands in this range. The sensor's speed is up to 50

full frames at 12 bits with $2 \mathrm{~nm}$ spectral resolution. The sensor in not equipped with cooling, but it allows $2 \times 2$ binning,

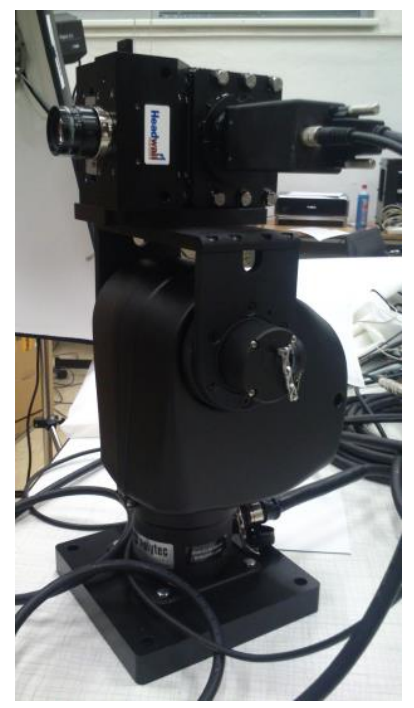

Figure 1- Hyperspectal instrument - Headwall Photonics, Inc. Hyperspec Aseries placed on Pan\&Tilt mobile unit 
which was not used in this case.

The hyperspectral instrument is placed on a medium size motorized moving platform designed by Headwall Photonics, Inc. named Pan\&tilt [15], that provides accurate real-time positioning of the hyperspectral equipment. The imaging spectrometer has been calibrated by the manufacturer.

Illumination was a big issue when dealing with historic paintings. The temperature of the painting must not exceed $35^{\circ} \mathrm{C}$, which was monitored using thermometer. Illumination was accomplished by two 500Watt Halogen lamps supplemented with one 150Watt infrared bulb.

\section{PAINTINGS}

Two different paintings were examined. Both pieces of art are oil paintings on wooden board. This combination was chosen because of the possibility of underdrawing visualization which is supposed to be the most uncomplicated painting combination for this type of analysis.

The first chosen painting for the analysis is by David II. Teniers and it belongs to the best that Flemish classical 17 th-century painting can offer. Teniers painted almost every kind of picture, but chiefly genre scenes of peasant life, which is typical subject for this historical period and the area, many of which were subsequently used for tapestry designs in the 18th century [16]. He was born in 1610 in Antwerp to the family with a long artistic tradition. His father David Teniers the Elder was respected painter, influenced directly by misters such as Rubens or Elsheimer. Early works of David II. Teniers shows also the influence of Adriaen Brouwer. He has achieved a great success already during his lifetime. Besides his prestigious position of the court painter of the Archduke Leopold Wilhelm, he was appointed as a keeper of the collection of pictures the Archduke was then forming. Finally he was of the prime movers of the foundation the Brussels Academy of Fine Arts (1663) and subsequently the Academy in Antwerp (1665). His artwork belongs to the golden age of Flemish and Duch painting. Especially his early works are of significant high quality. They are characterized by extreme ease of painting, fascinating effects of lights and shadows, perfect sense for detail, astonishing amount of acquired knowledge and natural good taste. All of these characteristics are relevant for chosen painting "Interior of a Mill". This oil on panel painting of medium size is dated 1633 approximately. It displays an interior of the old mill with a small figure in the background. We can notice the significant sense for detail and very delicate, limited range of colors. However Teniers was very skillful painter and his production was enormous. There are over 900 paintings accepted as original productions of Teniers. Few artists ever worked with greater ease, and some of his smaller pictures, landscapes with figures, have been called "afternoons", not from their subjects, but from the time spent in producing them. Although copying of successful motifs was very common in these times, maybe the high productivity of Teniers caused a slight stereotype in his later work. Despite this fact he has many followers and one of them is his favorite student Thomas van Apshoven (1622 and 1665).

The second piece of art was made by Terniers pupil Thomas van Apshoven. He lived also in Antwerpen between years 1622 and 1665. In most of the cases, Thomas van Apshoven imitated his master's style and his paintings can be easily mistaken. Also subjects of his paintings, like those of his master, are village festivals, interiors and genre scenes. [17]. Painting ,On the Road", the second chosen piece of art, is an oil painting on wooden board which displays classical scene of the Flemish countryside.

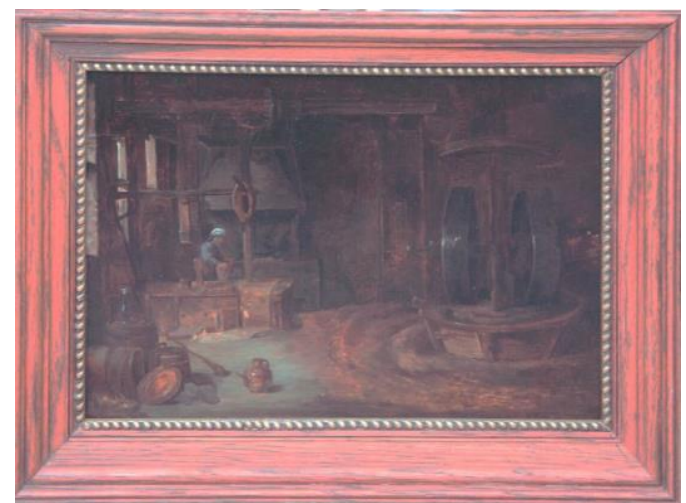

Figure 2 - Explored painting by David Ternier the Younger „, The Interieour of the Mill “ as seen in daylight

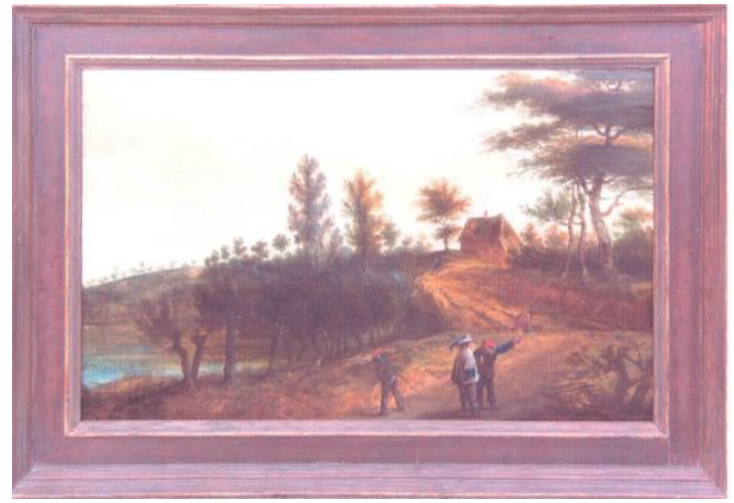

Figure 3 - Explored painting by Thomas van Apshoven "On the Road" as seen in daylight

\section{RESULTS}

The painting was placed on an easel in front of the hyperspectral sensor and illuminated as mentioned above. The scanning distance was set to $1,5 \mathrm{~m}$, so the pixel size is $0.33 \mathrm{~mm}$. The piece of art had to be treated with big care, because when illuminated by too powerful instruments for a long time the oil can be affected or even destroyed. The maximum temperature cannot exceed $35^{\circ} \mathrm{C}$ or a serious damage can occur. The illumination parameters were discussed with the manufacturer and used as mentioned above. The temperature of the painting was observed by a thermometer and cooling was performed by a fan. Ventilation of the air next to the scanned painting and the temperature did not exceed $30^{\circ} \mathrm{C}$. The scanning speed was set to the minimum $(10$ frames $/ \mu \mathrm{m})$ and the exposure time to maximum $(40,23 \mu \mathrm{m})$ to enable the maximum light to come to the detector. Scanning angle and the number of frames had to be set to cover the entire image. White and dark reference was performed by the XCAP software provided by the manufacturer.

One detail was used for each painting. Details were chosen in respect to IR reflectography and the visibility of underdrawings. For Ternier it was the low-left corner showing barrels and the millers working desk (see figure 4) and for Van Apshoven it was the house on the horizon in the right half of the painting (see figure 5). The details are a RGB image synthesis as derived from hyperspectral image $(\operatorname{Red} \lambda=629,93 \mathrm{~nm}$; Green $\lambda=529,89 \mathrm{~nm} ;$ Blue $\lambda=449,87 \mathrm{~nm})$ 


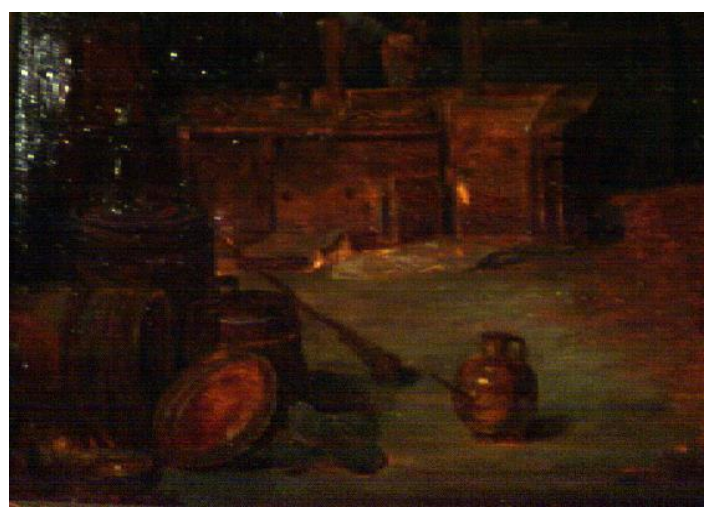

Figure 4 - Detail of Ternier's painting

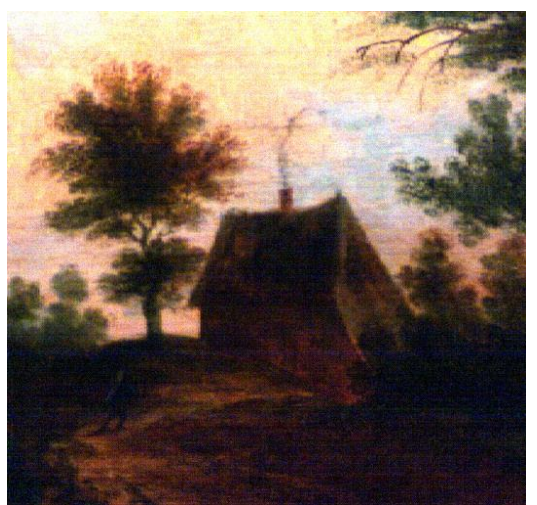

Figure 5 - Detail of Van Apshoven's painting

ENVI software was used for the image processing. Different calibration techniques were used in this study. After importing the data into the software usual pre-processing methods were performed and mathematical approach has been accomplished. Various change detection [18] and RX anomaly detection [19] algorithms in between wavelengths 700 to 900 $\mathrm{nm}$ were used with the majority of unsatisfied results. These techniques show an interesting perspective to explored paintings, but do not show underdrawings as desired. For the underdrawing detection the Principal Components were computed from the data as mentioned in [20]. One can see individual components as well as their RGB synthesis. It was discovered, that principal components demonstrate different aspects (in VNIR region we talk mainly about colour) of the drawing. Unfortunately in our analysis an extended infrared region is missing, so the Principal components do not include similar information an IR reflectography. When compared to IR images one can see that underdrawings are present and visible. For better visualization of the results various filtering methods were analyzed. Low and high pass filters were found as suitable and therefore performed to derive more complex image. RGB synthesis of principal components on image details are shown on figures 6,9 and 11 .

Representative result can be seen on Ternier's painting when analysing the receptacle in the middle-right of figure 4 . The pseudo-color image of three principal components (figure 6) shows, that the author made some changes on the vessel. Originally the object was much smaller (dark purple) and was enlarged later in the work. These changes can be aso seen in ultraviolent light. Unfortunately they are not always so clear and PCA can give better hint for places of interest when painting documentation.

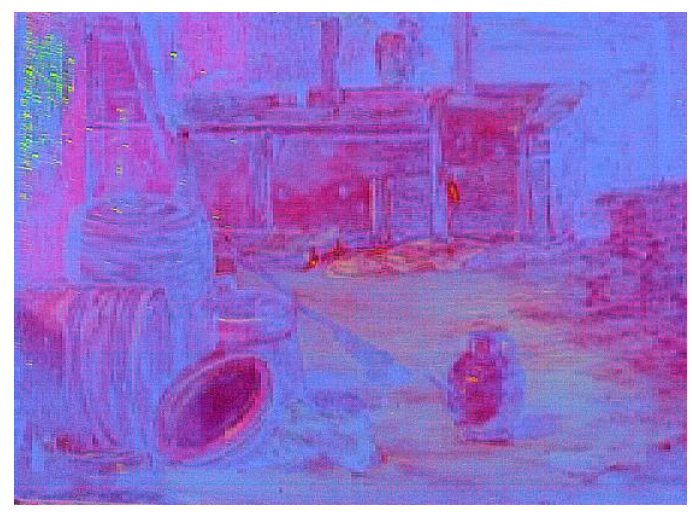

Figure 6 - Pseudo-color image of three Principal components of the drawing (PC4 - Red, PC2 - Green, PC1 - Blue) derived from hyperspectral data - Ternier

IR reflectography was done in cooperation with academic painter Mr. M. Martan and his special CCD Hamamtsu camera in $1500-1800 \mathrm{~nm}$ wavelengths. See Firures 7 and 8 for Ternier and 10 for Van Apshoven. These images have not been mathematically adjusted.
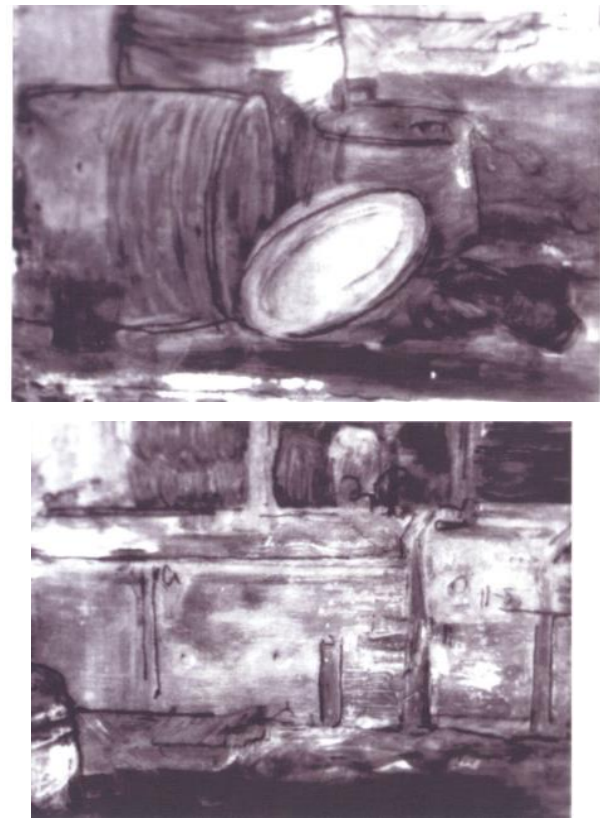

Figure 7, 8 Details of the Ternier's painting using infrared reflectography $(1500-1800 \mathrm{~nm})$

Hyperspectral data are widely used to determine the spectral profile of certain object. It was found, that illumination is a great issue. When gaining data from a darker point, the amount of photons coming through the camera entrance slit need to be sufficient. When this assumption is not fulfilled the pixel values are low and the data are very noisy. In our previous analysis two 300 Watt halogen lights were used and it was discovered, that more powerful illumination is needed. As mentioned above, two 500W halogen lights were used in this case after discussing with experts. New results still show shortage of illumination. When dark pixel is analyzed it covers very low pixel values, which leads to high noise.

The problem with illumination cannot be set by simple adding more and more illumination sources. Each halogen bulb emits a lot of heat, which can seriously harm the painting. Finding the appropriate illumination source that gives 
enough light but does not damage the cultural heritage object is one of our future challenges.

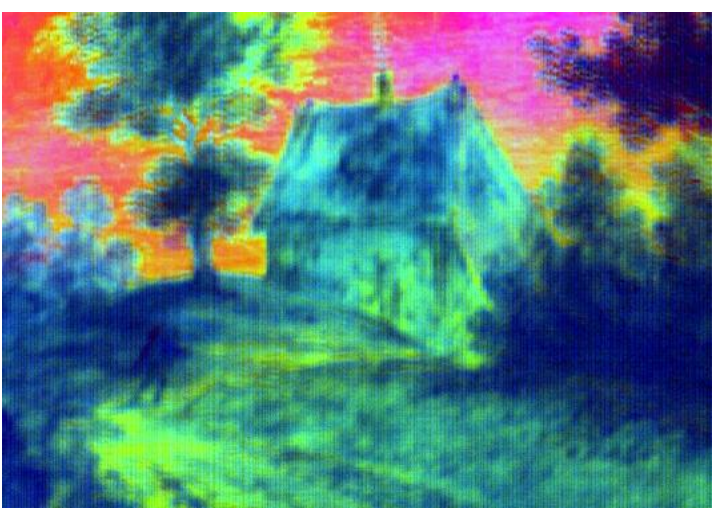

Figure 9 - Pseudo-color image of three Principal components of the drawing (PC1 - Red, PC2 - Green, PC3 - Blue) derived from hyperspectral data - Van Apshoven

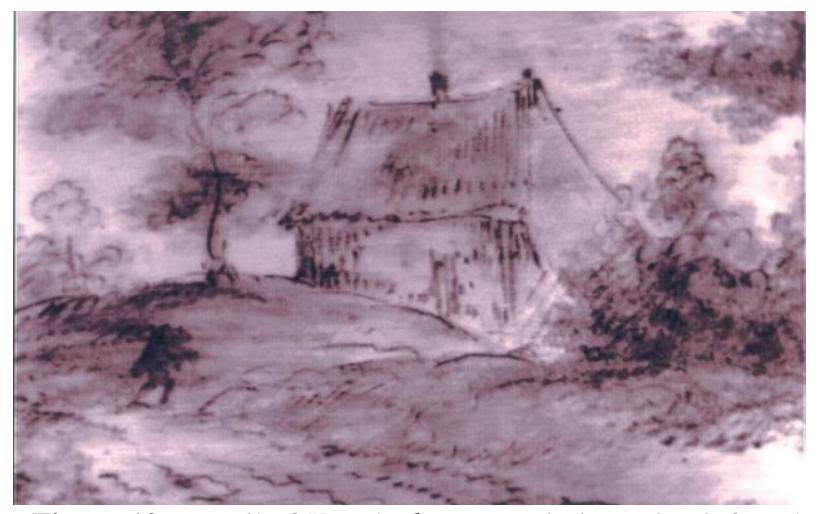

Figure 10 - Detail of Van Apshoven's painting using infrared reflectography $(1500-1800 \mathrm{~nm})$

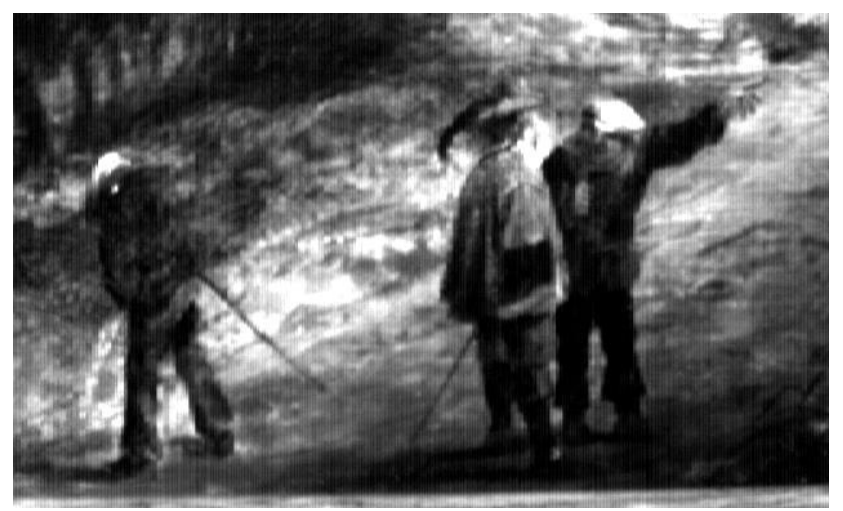

Figure 11 - Inverse image of the first principal component of the drawing derived from hyperspectral data - Van Apshoven

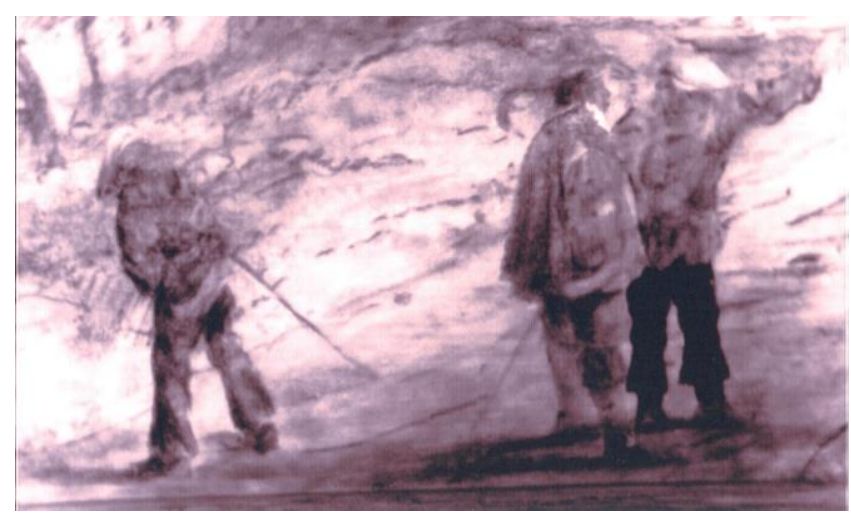

Figure 12 - Detail of Van Apshoven's painting using infrared reflectography $(1500-1800 \mathrm{~nm})$

\section{CONCLUSIONS}

Hyperspectral analysis using VNIR (400-1000nm) camera was performed on two $17^{\text {th }}$ century paintings. The comparison with IR reflectography was conducted and interesting results are shown. The goal was to detect and visualize the underdrawings made by the author. Several mathematical approaches were tested and it was found, that principal component analysis can be used for this matter in certain cases. When compared to IR reflectography it is not so powerful because of the data shortage in extended infrared region. These data would allow us to go deeper into the painting and the following analysis would be attractive. Regarding this issue other funding sources are to be found for extended VNIR or SWIR instruments. On the other hand, this spectral lack is the motivation for discovering of new possibilities in VNIR region.

First results of the new cultural heritage project were shown together with future challenges. In the next step of this project the new illumination sources need to be found, so that the investigated object will not be affected by the negative aspects and that the analysis could be certainly called noninvasive.

\section{ACKNOWLEDGEMENT}

Authors would like to thank to an academic painter Mr. Martin Martan for the support and lending of paintings as well as the Ministry of Culture in the Czech Republic for project funding. 


\section{REFERENCES}

[1]

Pavelka, K.: Photogrammetrical Documentation of Historical Monuments. Zeměměř ič. 2002, roč. 9, č. 12, s. 1821. ISSN 1211-488X.

[2] ZASTOUPIL, Jaroslav et al. MEASURED SURVEY AND DIGITAL PHOTOGRAMMETRY METHODS DURING THE RESTORATION OF THE MAIN DOME DECORATION IN THE PILGRIMAGE CHURCH OF ST. JOHN OF NEPOMUK AT ZELENÁ HORA IN ŽĎÁR NAD SÁZAVOU. CIPA heritage documentation: Past Symposia Digital proceedings [online]. 2011, č. 1 [cit. 2013-04-24]. Available

from: http://cipa.icomos.org/fileadmin/template/doc/PRAGUE/159.pd f

[3] BOEHLER, W. Et al. The potentials of noncontact close range laser scanners for cultural heritage recordings. CIPA heritage documentation: Past Symposia Digital proceedings [online]. 2001[cit. 2013-04-29]. Available from: mainz.de/publicat/cipa2001/cipa2001.pdf http://www.i3mainz.fh-

[4]

DONEUS, M. et al. Terrestrial waveform laser scanning for documentation of cultural heritage. CIPA heritage documentation: Past Symposia - Digital proceedings [online]. 2009, č. 1 [cit. 2013-04-24]. Available from: http://cipa.icomos.org/fileadmin/template/doc/KYOTO/48.pdf

[5]

FALTYNOVA, Martina. Documentation of Corpus Christi chapel in Kutna Hora by laser scanning technology. CIPA heritage documentation: Past Symposia Digital proceedings [online]. 2011, č. 1 [cit. 2013-04-24]. Available

from: http://cipa.icomos.org/fileadmin/template/doc/PRAGUE/048.pd $\mathrm{f}$

[6] DOLANSKY, Tomas et al. Detailed documentation of synagogues in Prague using combination of tachymetry, laser scanning and clore-range prohogrammetry. CIPA heritage documentation: Past Symposia - Digital proceedings [online]. 2011, č. 1 [cit. 2013-04-24]. Dostupné z: http://cipa.icomos.org/fileadmin/template/doc/PRAGUE/162.pd f

[7] YASTIKLI, Naci. Documentation of cultural heritage using digital photogrammetry and laser scanning. Journal of Cultural Heritage [online]. 2007, roč. 8, č. 4, s. 423427 [cit. 2013-04-30]. Available from: http://www.sciencedirect.com/science/article/pii/S12962074070 01082

[8] JORDA, Francisco et al. Close range photogram,metry and terrestrial laser scanning: high resolution texturized 3D model of The Chapel of the kings in The Palencia Cathedral as a case study. CIPA heritage documentation: Past Symposia - Digital proceedings [online]. 2011, č. 1 [cit. 201304-24]. Available from: http://cipa.icomos.org/fileadmin/template/doc/PRAGUE/079.pd f

[9] JOCHIN, T. et al. Steamless usage of user's databases in archaeological database system. CIPA heritage documentation: Past Symposia - Digital proceedings [online]. 2009, č. 1 [cit. 2013-04-24]. Available from: http://cipa.icomos.org/fileadmin/template/doc/KYOTO/121.pdf

[10] PAPPA, K. et al. Record, analysis and documentation using GIS applications for the institutional protection of Enoria settlement in Greece. CIPA heritage documentation: Past Symposia - Digital proceedings [online]. 2009, č. 1 [cit. 2013-04-24]. Available from: http://cipa.icomos.org/fileadmin/template/doc/KYOTO/176.pdf

[11] GILLOT, L. and DEL, A. Preparation and submission of the nomination file of The Oasis of Figuig (Morocco) for inscription on the world heritage list: impacts and uses of a GIS. CIPA heritage documentation: Past Symposia - Digital proceedings [online]. 2011, č. 1 [cit. 201304-24]. Available from: http://cipa.icomos.org/fileadmin/template/doc/PRAGUE/059.pd f

[12] LIANG, Haida. "Advances in multispectral and hyperspectral imaging for archaeology and art conservations". Applied Physics A: Material Science \& Processing., SpringerVerlag, vol. 106, pp. 309-323, 2012.

[13] ATTAS, Michael et al. "Near-infrared spectroscopic imaging in art conservation: investigation of drawing constituents" Journal of Cultural Heritage, Elsevier, vol.4, pp. 127-136., 2003

[14] HEADWALL PHOTONICS, Inc. Hyperspectral Imaging Sensors: Hyperspec VNIR [online]. 2013 [cit. 2013-02-14]. Available from: http://www.headwallphotonics.com/hyperspectral

[15] HEADWALL PHOTONIC, Inc. Hyperspec Pan\&Tilt [online]. [cit. 2013-02-14]. Available from: http://www.headwallphotonics.com/Portals/145999/docs/ds_hy perspec\%20pan\%20\&\%20tilt.pdf

[16] Encyclopaedia Britannica. ENCYCLOPÆDIA

BRITANNICA, Inc. David Teniers, the Younger [online]. 2008, 2009 [cit. 2013-04-29]. Available from:

http://www.britannica.com/EBchecked/topic/587269/DavidTeniers-the-Younger

[17] APSHOVEN, Thomas van. Bryan's Dictionary of Painters and Engravers. 1886-1889. London: George Bell and Sons, 1886. Available from:

http://www.archive.org/stream/cu31924092716962\#page/n5/mo de/2uphttp://www.archive.org/stream/cu31924092716962\#page /n5/mode/2up

[18] ENVI online help: Change Detection Analysis. Geol.hu [online]. 2005 [cit. 2013-04-30]. Available from: ttp://geol.hu/data/online_help/ChangeDetectionAnalysis.html

[19] RX (Reed-Xiaoli) Anomaly Detection in ENVI. EXELIS VISUAL INFORMATION SOLUTION. Support: $R X$ (Reed-Xiaoli) Anomaly Detection in ENVI [online]. 2006 [cit. 2013-04-30]. Available from: http://www.exelisvis.com/Support/HelpArticlesDetail/TabId/21 9/ArtMID/900/ArticleID/3991/3991.aspx

[20] MANSFIELD, James R., et al. "Near infrared spectroscopic reflectance imaging: a new tool in art conservation" Vibrational Spectroscopy, Elsevier, vol.28, pp. 59-66., 2002 